\title{
Association between vitamin B12 and non-alcoholic fatty liver disease: a case control study in Katra Jammu
}

\author{
Chandan Sharma ${ }^{1}$, Ashima Badyal ${ }^{2 *}$
}

\author{
${ }^{1}$ Sub-District Hospital, Akhnoor, Jammu, Jammu and Kashmir, India \\ ${ }^{2}$ Department of Biochemistry, Government Medical College, Jammu, Jammu and Kashmir, India
}

Received: 05 May 2021

Accepted: 21 May 2021

\author{
*Correspondence: \\ Dr. Ashima Badyal, \\ Email: badyal.ashima@gmail.com
}

Copyright: ( $)$ the author(s), publisher and licensee Medip Academy. This is an open-access article distributed under the terms of the Creative Commons Attribution Non-Commercial License, which permits unrestricted non-commercial use, distribution, and reproduction in any medium, provided the original work is properly cited.

\begin{abstract}
Background: Non-alcoholic fatty liver disease (NAFLD) is currently the most common chronic liver disease in developed countries and obesity contributing maximum to the disease load. A reduction in the energy content of diet, alone, may not prevent NAFLD, nor could alleviate it. Recent studies are bringing to light the association, importance and role of dietary vitamins and liver fat accumulation. Vitamin B12 is involved in the metabolism of every cell of the human body. It is a cofactor in DNA synthesis and in both fatty acid and amino acid metabolism. Still, the influence of vitamin B12 deficiency on NAFLD has not been studied much.

Methods: A case control observational study was conducted in the department of medicine, community health center, Katra during the period of August 2018 to July 2019. The study was conducted on 150 NAFLD patients and 50 aged and gender-matched healthy controls. Patients showing ethanol consumption, liver cirrhosis, DM, pancreatitis, renal failure or cancer were excluded.

Results: Patients and controls almost matched in all clinical examinations like fever, jaundice, nausea, but vitamin B12 levels were significantly low among cases and stood at $377.60 \pm 181.43 \mathrm{pg} / \mathrm{ml}$ as against $548.28 \pm 285.70$ for controls, but still remained within the reference range. Vitamin D levels were also found to be lower among cases. B12 deficiency is extremely common in India with an estimated prevalence of $47 \%$ and more males tend to have NAFLD than females. Conclusions: For better management of the disease, vitamin B12 levels should be assessed in all NAFLD patients.
\end{abstract}

Keywords: Vitamin B12, Non-alcoholic fatty liver disease, Obesity, Vitamin D

\section{INTRODUCTION}

NAFLD is currently the most common chronic liver disease in developed countries and obesity contributes maximum to this disease load. ${ }^{1}$ This disease increases the risk for co-morbidities like type 2 diabetes (T2DM) and cardiovascular disease and is greatly responsible for liverrelated morbidity and mortality. Metabolic syndrome including insulin resistance, together with adverse genetic, hormonal and lifestyle factors is a kind of trigger that often precipitates to the development of NAFLD. ${ }^{2}$ NAFLD is defined as the presence of $\geq 5 \%$ steatosis in the absence of secondary causes of fat accumulation in the liver. The disease starts with fatty liver or hepatic steatosis and may progress to steatohepatitis with hepatic inflammation. ${ }^{3}$ Five to twenty percent of patients with fatty liver develop nonalcoholic steatohepatitis (NASH) in their clinical course, of which $10-20 \%$ develop into higher-grade fibrosis and $<5 \%$ progress to full blown cirrhosis. ${ }^{4}$ In the western world, NAFLD continues to be the most common liver disease, with rising incidence, mainly due to the sedentary life style, high fatty food and the accompanying obesity. Current global prevalence of NAFLD is $10.9 \%$, higher in patients with a background of T2DM or with metabolic syndrome. ${ }^{5}$ 
A reduction in the energy content of diet, by itself alone, may not prevent NAFLD, nor could alleviate it. Dietary compositions, both macronutrient and micronutrient, may also be playing a crucial role in the manifestation and development of NAFLD. Recent studies are bringing to light the association, importance and role of dietary vitamins and liver fat accumulation. Vitamins are essential micronutrients which help in the buildup and maintenance of health status of a person. Vitamin B12 or cobalamine is water soluble cobalt containing vitamin. Vitamin B12 is a cofactor for two enzymes. Firstly, in the cytoplasm, methionine synthase requires vitamin B12 in the form of methylcobalamin and catalyzes the conversion of homocysteine to methionine by transfer of a methyl group from methyltetrahydrofolate. Secondly, in the form of 5'deoxyadenosylcobalamin, vitamin B12 is also required for the mitochondrial enzyme methylmalonyl, important for the oxidation of odd-chain fatty acids and catabolism of ketogenic amino acids. ${ }^{6}$

Vitamin B12 is involved in the metabolism of every cell of the human body. It is one of eight B vitamins. It is a cofactor in DNA synthesis and in both fatty acid and amino acid metabolism. ${ }^{7}$ Unlike most other vitamins, B12 is stored in substantial amounts, mainly in the liver, until it is needed by the body. It is largely understood that the body's stores of this vitamin usually take about 3 to 5 years to exhaust. ${ }^{8,9}$ Besides, several liver diseases such as acute hepatitis, alcohol hepatitis, liver cirrhosis and hepatocellular carcinoma have been associated with changes in plasma vitamin B12 by different pathways. ${ }^{10,11}$ But, the influence of vitamin B12 deficiency on NAFLD has not been studied much. Very little studies have been conducted to assess this relationship in India and none in the geographical region defined by Katra (Jammu). Therefore, the study aimed to study this relationship and was planned to evaluate serum vitamin B12 levels in patients with NAFLD and their association with disease severity.

\section{METHODS}

This case control observational study was conducted in the OPD of department of medicine during the period of August 2018 to July 2019 in community health center, Katra, Jammu, Jammu and Kashmir, India. The study was conducted on randomly selected 200 subjects. 150 NAFLD patients of either gender, in the age group of 19 and above years and 50 aged and gender-matched healthy controls selected from the attendants of the patients visiting the OPD. Written informed consent was taken from all participants before their enrollment in the study. Ethical clearance was obtained from IEC and the study protocol conformed to the ethical guidelines. Medical history, physical examination and standard tests and procedures were performed during the screen visits of patients for determining their eligibility for the study. To rule out other possible liver diseases, both cases and controls were evaluated by abdominal ultrasonography, clinical and laboratory findings as well.

\section{Inclusion criteria for NAFLD patients (cases)}

Patients with age $>18$ years, bright liver on ultrasound imaging, increased liver function tests for at least 6 months before enrolment and patients consenting for liver biopsy were included in the study.

\section{Inclusion criteria for healthy controls}

Age, gender and body mass index (BMI) matched individuals with normal liver ultrasound imaging and normal liver function test were included in the study.

\section{Exclusion criteria}

Patients having ethanol consumption for more than 20 g/day, patients with liver cirrhosis, any other liver disease (viral hepatitis, autoimmune hepatitis and sclerosis), patients having T2DM, pancreatitis, uncontrolled hypothyroidism or hyperthyroidism, renal failure, cancer, patients who are pregnant and patients with addiction to any drug or use of folate or on regula vitamin B supplementation were excluded from the study.

Serum AST, ALT, GGT, HDL-C, triglycerides, total cholesterol, glucose and vitamin B12 were measured by immunochemiluminescence by ADVIA Centaur immunoassay system. BMI was calculated by the formula,

body weight $=\frac{(\mathrm{kg})}{\text { height }(\mathrm{m})^{2}}$.

Data was analysed and statistical calculations were carried out using Microsoft excel 2010 software. Mean \pm standard deviation, median was found out to appropriately represent the data. $\mathrm{P}$ value of $<0.05$ was considered significant.

\section{RESULTS}

Mean age of patients was $44.65 \pm 9.43$ years. Out of the 150 subjects studied as cases, 69 were females, while there were 19 females (out of 50 subjects studied) under controls group (Figure 1). There was not much significant difference between NAFLD patients and controls regarding age (44.65 \pm 9.43 years; $44.21 \pm 8.73$ years), however slightly significant difference of data values were found for hemoglobin and platelet count among them. BMI also seemed to be an important variant among them here (Table 1).

Patients and controls almost matched in all clinical examinations like fever, jaundice, nausea, constipation or diarrhea (Table 2). Vitamin B12 levels in cases showed up as a significant factor of differentiation among the two groups $(\mathrm{p}<0.001)$, serum cholesterol, triglycerides also differing significantly $(\mathrm{p}<0.05)$ (Table 3$)$. 


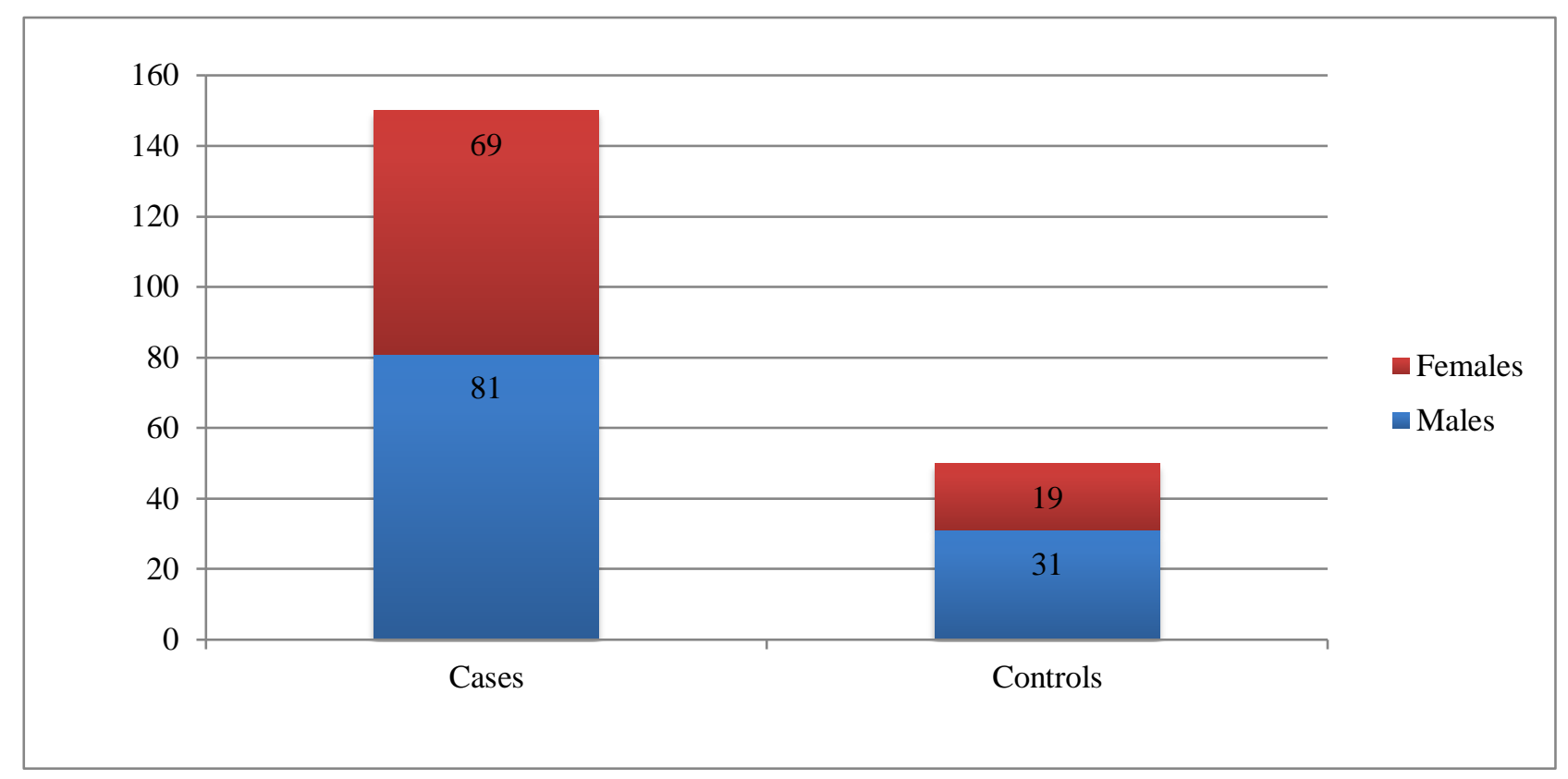

Figure 1: Demographic distribution of study groups.

Table 1: General parameters of patients and controls $(n=200)$.

\begin{tabular}{|c|c|c|c|c|c|c|}
\hline \multirow{2}{*}{ S. no. } & \multirow{2}{*}{ Parameters } & \multicolumn{2}{|c|}{ Cases $(n=150)$} & \multicolumn{2}{|c|}{ Controls $(\mathrm{n}=\mathbf{5 0})$} & \multirow[t]{2}{*}{$P$ value } \\
\hline & & Mean & SD & Mean & SD & \\
\hline 1 & Age & 44.65 & 9.43 & 44.21 & 8.73 & 0.7627 \\
\hline 2 & Body mass index (BMI) & 29.44 & 3.06 & 28.53 & 2.89 & 0.0589 \\
\hline 3 & Hemoglobin $(\mathrm{gm} / \mathrm{dl})$ & 11.45 & 1.51 & 11.98 & 1.64 & $0.045^{*}$ \\
\hline 4 & Red blood cells count (RBC) (million cells per mcl) & 3.868 & 0.882 & 4.017 & 0.896 & 0.3079 \\
\hline 5 & White blood cells count (WBC) (number per mcl) & 8756 & 1970 & 8954 & 372.84 & 0.2435 \\
\hline 6 & Platelet count (number per mcl) & 186300 & 21500 & 193400 & 22200 & $0.0498 *$ \\
\hline
\end{tabular}

Table 2: Basic clinical examinations of patients and controls.

\begin{tabular}{|c|c|c|c|c|}
\hline S. no. & Parameters & Cases & Control & $P$ value by Chi test \\
\hline \multirow[t]{3}{*}{1} & Fever & & & \\
\hline & Yes & 25 & 7 & \multirow{2}{*}{0.6560} \\
\hline & No & 125 & 43 & \\
\hline \multirow[t]{3}{*}{2} & Jaundice & & & \\
\hline & Yes & 13 & 5 & \multirow{2}{*}{0.7754} \\
\hline & No & 137 & 45 & \\
\hline \multirow[t]{3}{*}{3} & Bleeding tendency & & & \\
\hline & Yes & 2 & 0 & \multirow{2}{*}{0.4119} \\
\hline & No & 148 & 50 & \\
\hline \multirow[t]{3}{*}{4} & Fatigue & & & \\
\hline & Yes & 52 & 15 & \multirow{2}{*}{0.5449} \\
\hline & No & 98 & 35 & \\
\hline \multirow[t]{3}{*}{5} & Nausea & & & \\
\hline & Yes & 33 & 9 & \multirow{2}{*}{0.5476} \\
\hline & No & 117 & 41 & \\
\hline \multirow[t]{3}{*}{6} & Constipation/diarrhea & & & \\
\hline & Yes & 14 & 4 & \multirow{2}{*}{0.7754} \\
\hline & No & 136 & 46 & \\
\hline
\end{tabular}


Table 3: B12 levels, lipid profile and liver functions in patients and controls $(n=200)$.

\begin{tabular}{|c|c|c|c|c|c|c|}
\hline \multirow{2}{*}{ S. no. } & \multirow{2}{*}{ Parameters } & \multicolumn{2}{|c|}{ Cases $(n=150)$} & \multicolumn{2}{|c|}{ Controls $(\mathrm{n}=\mathbf{5 0})$} & \multirow{2}{*}{$P$ value } \\
\hline & & Mean & SD & Mean & SD & \\
\hline 1 & Vitamin B12 (pg/ml) & 377.6 & 181.43 & 548.28 & 285.7 & $0.0001 *$ \\
\hline 2 & Cholesterol (mmol/l) & 7.5 & 1.08 & 6.74 & 1.53 & $0.0013^{*}$ \\
\hline 3 & Triglycerides $(\mathrm{mmol} / \mathrm{l})$ & 3.1 & 1.21 & 2.61 & 1.02 & $0.0056^{*}$ \\
\hline 4 & ALT (IU/l) & 85.02 & 33.92 & 31.29 & 10.46 & $<0.0001 *$ \\
\hline 5 & AST (IU/l) & 101.06 & 45.33 & 33.48 & 12.35 & $<0.0001 *$ \\
\hline
\end{tabular}

*p $<0.05=$ significant; $\mathrm{p}<0.001=$ very significant.

Table 4: Vitamin D level, diabetes, IBD and PPI use-variation among patients and controls.

\begin{tabular}{|c|c|c|c|c|}
\hline S. no. & Associated risk factor & Cases & Control & P value by Chi test \\
\hline \multirow{3}{*}{1} & Vitamin D level & & & \\
\hline & Low & 122 & 29 & \multirow{2}{*}{$0.0009^{*}$} \\
\hline & Normal & 28 & 21 & \\
\hline \multirow{3}{*}{2} & Diabetes mellitus & & & \\
\hline & Yes & 65 & 20 & \multirow{2}{*}{0.6797} \\
\hline & No & 85 & 30 & \\
\hline \multirow{3}{*}{3} & IBD & & & \\
\hline & Yes & 88 & 22 & \multirow{2}{*}{0.0710} \\
\hline & No & 62 & 28 & \\
\hline \multirow{3}{*}{4} & PPI use & & & \\
\hline & Yes & 73 & 24 & \multirow{2}{*}{0.9349} \\
\hline & No & 77 & 26 & \\
\hline
\end{tabular}

$* \mathrm{p}<0.001=$ significant $*$ there is a significant difference in vitamin D levels in NAFLD patients and controls.

There was a significant variation among patients and controls with $122(81.33 \%)$ of patients having lower vitamin D levels as compared to only 29 (58\%) among healthy controls, however, number of patients with diabetes mellitus and proton pump inhibitors (PPI) use to relieve symptoms of acid reflux or gastro-esophageal reflux disease (GERD) was almost similar among the two. Inflammatory bowel disease (IBD) was showing in 88 patients $(58.67 \%)$, which was also quite higher to $44 \%$ prevalence among controls (Table 4).

\section{DISCUSSION}

B12 deficiency is extremely common in India as is vitamin $\mathrm{D}$, folic acid or iron deficiency. This is because malnutrition is extremely common and related to diet, lifestyle and social and cultural issues. In spite of being a common disorder, its recognition is missed because the manifestations are diverse in nature, affecting all the organs and systems and is often subclinical. Laboratory estimations are often unreliable and doctors tend to rely on laboratory estimate of B12 levels..12 As an estimate, prevalence of vitamin B12 deficiency is at least $47 \%$ in Indian population and only $26 \%$ population may be vitamin B12 sufficient if people with levels between $200-300 \mathrm{pg} / \mathrm{ml}$ are considered borderline deficient. ${ }^{13}$ Lindsay et al in 2008 in the US, showed that the prevalence of vitamin B12 deficiency (serum vitamin B12<148 pmol/l) varied with age. It affected less than 3\% of those aged 20-39 years and up to $6 \%$ of persons aged more than 70 years. ${ }^{14} \mathrm{~B} 12$ levels between 160 and $200 \mathrm{ng} / \mathrm{l}$ but up to $1000 \mathrm{ng} / \mathrm{l}$ can be normal but is false normal in majority of cases, especially if it is an autoimmune etiology, serum methyl malonic acid (MMA) is elevated $(950 \mathrm{nmol} / \mathrm{l})$ most often and is said to be more specific. Serum MMA could be used for early diagnosis, even in the absence of hematological abnormalities. ${ }^{15-17}$

Vitamin B12 deficiency may be related to various causes such as insufficient nutritional intake due to vegetarian diets or increased metabolic demands among pregnant and lactating women. It can also be related to the malabsorption syndrome. Chronic pancreatitis could also reduce pancreatic enzyme secretion, leading to impaired degradation of HC-bound vitamin B12 and vitamin B12 trapping. Kavimandan et al in 2013 had related the low vitamin B12 levels, detected among Indian patients, to the prevalence of tropical sprue. ${ }^{18}$

In our study, we found that patients with NAFLD have low vitamin B12 level. In a similar study with a comprehensive and comparative analysis, vitamin B12 levels were found significantly low among Saudis and Jordanian compared to other nationalities. The mean vitamin B12 levels in Saudis were $367.5 \mathrm{pg} / \mathrm{l}$ ranking lowest after Jordanians and Indians. ${ }^{19}$ In Western countries, NAFLD is the most common liver disease with a prevalence of $20-30 \% .{ }^{20}$ Foster et al in 2013 showed a prevalence of $24 \%$ in the United States of America with more prevalence in African Americans. ${ }^{21}$ A study by Kopley et al in 2011 and Abdullah 
et al in 2015 found that more males $(54.7 \%)$ have NAFLD than females $(45.2 \%)$ and that serum vitamin B12 levels were significantly lower in the patients with NAFLD than in those of the control group, but remained within the reference range. ${ }^{10,19}$ Koplay et al in 2011 also concluded that low vitamin B12 levels could be associated with NAFLD especially in grade 2 to grade 3 hepatosteatosis. ${ }^{10}$

Polyzos et al in 2012 measured serum vitamin B12 and folate levels in patients with biopsy proven NAFLD and their association with the disease severity. ${ }^{22}$ Furthermore, vitamin B12 and folate levels were not associated with either insulin resistance or the severity of liver disease. Our study obtained similar results with lower vitamin B12 and folate levels were observed in non-alcoholic steatohepatitis and non-alcoholic fatty liver patients.

The course and content of this present study also revealed a significant relation of low serum vitamin D with nonalcoholic fatty liver disease and similar studies are there to suggest low serum vitamin D causing NAFLD. Hypovitaminosis D is seemed to be associated with the severity and incidence of NAFLD. ${ }^{23}$

The limited geographical outreach of the community health center, in which it was conducted was a major limitation of the current study. Besides, there was very little prior research and investigations on the topic worldwide, to be able to directly compare the results and outcomes with.

\section{CONCLUSION}

Vitamin B12 levels were found lower in NAFLD patients, makes it important to assess vitamin B12 levels in all NAFLD patients for better management of the disease. More such studies are required to be conducted in a larger geographical and demographical expanse and more investigations are required to understand whether supplementation of vitamin B12 to patients with NAFLD could improve their health status.

Funding: No funding sources Conflict of interest: None declared

Ethical approval: The study was approved by the Institutional Ethics Committee

\section{REFERENCES}

1. Caldwell SH, Crespo DM. The spectrum expanded: cryptogenic cirrhosis and the natural history of nonalcoholic fatty liver disease. J Hepatol. 2004;40(4):578-84.

2. Pappachan JM, Babu S, Krishnan B, Ravindran NC. Non-alcoholic fatty liver disease: a clinical update. J Clin Transl Hepatol. 2017;5(4):384-93.

3. Nassir F, Rector RS, Hammoud GM, Ibdah JA. Pathogenesis and prevention of hepatic steatosis. Gastroenterol Hepatol (N Y). 2015;11(3):167-75.
4. Bataller R, Rombouts K, Altamirano J, Marra F. Fibrosis in alcoholic and nonalcoholic steatohepatitis. Best Pract Res Clin Gastroenterol. 2011;25(2):231-44.

5. Ge X, Zheng L, Wang M, Du Y, Jiang J. Prevalence trends in non-alcoholic fatty liver disease at the global, regional and national levels, 1990-2017: a populationbased observational study. BMJ Open. 2020;10(8).

6. Green R, Miller JW. Vitamin B12. In: Zemplini J, Rucker RB, Suttie JW, McCormick DB, eds. Handbook of vitamins. 2nd ed. Boca Raton, FL: CRC Press; 2007: 413-57.

7. Yamada K. (2013). Cobalt: its role in health and disease. Met Ions Life Sci. 2013;13:295-320.

8. Lieberman M, Marks AD. Tetrahydrofolate, vitamin B12 and S-adenosylmethionine. In: Lieberman M, Marks AD, eds. Mark's basic medical biochemistry: a clinical approach. 3rd ed. Philadelphia, PA: Wolters Kluwer/Lippincott Willaims and Wilkins; 2009.

9. Institute of medicine (US) standing committee on the scientific evaluation of dietary reference intakes and its panel on folate, other B vitamins, and choline. Dietary reference intakes: thiamin, riboflavin, niacin, vitamin B6, folate, vitamin B12, pantothenic acid, biotin, and choline. Washington, DC: National Academy Press; 1998.

10. Koplay M, Gulcan E, Ozkan F. Association between serum vitamin B12 levels and the degree of steatosis in patients with nonalcoholic fatty liver disease. $\mathrm{J}$ Investig Med. 2011;59(7):1137-40.

11. Cylwik B, Czygier M, Daniluk M, Chrostek L, Szmitkowski M. Vitamin B12 concentration in the blood of alcoholics. Pol Merkur Lekarski. 2010;28(164):122-5.

12. Sasidharan PK. B12 deficiency in India. Arch Med Health Sci. 2017;5(2):261-8.

13. Singla R, Garg A, Surana V, Aggarwal S, Gupta G, Singla S. Vitamin B12 deficiency is endemic in indian population: a perspective from North India. Indian $\mathbf{J}$ Endocrin Metab. 2019;23(2):211-4.

14. Allen LH. How common is vitamin B12 deficiency? Am J Clin Nutr. 2009;89(2):693-6.

15. Yang DT, Cook RJ. Spurious elevations of Vitamin B12 with pernicious anemia. $N$ Engl $J$ Med. 2012;366:1742-3.

16. Carmel R, Agrawal YP. Failures of cobalamin assays in pernicious anemia. $\mathrm{N}$ Engl $\mathrm{J}$ Med. 2012;367(4):385-6.

17. Stabler SP, Marcell PD, Podell ER, Allen RH, Lindenbaum J. Assay of methylmalonic acid in the serum of patients with cobalamin deficiency using capillary gas chromatography-mass spectrometry. J Clin Invest. 1986;77(5):1606-12.

18. Kavimandan A, Sharma M, Verma AK, et al. Prevalence of celiac disease in nutritional anemia at a tertiary care center.

19. Al-Quaydheb AN, Ofaysan MSB, Rasheed AAL. Relation between vitamin B12 and Non-alcoholic fatty liver disease: a hospital based study. Int J Adv Res. 2015;3(6):1335-43. 
20. Bellentani S, Scaglioni F, Marino M, Bedogni G. Epidemiology of non-alcoholic fatty liver disease. Digest Dis. 2010;28(1):155-61.

21. Foster T, Anania FA, Li D, Katz R, Budoff M. The prevalence and clinical correlates of nonalcoholic fatty liver disease (NAFLD) in African Americans: the multiethnic study of atherosclerosis (MESA). Digest Dis Sci. 2013;58(8):2392-8.

22. Polyzos SA, Kountouras J, Patsiaoura K, Katsiki E, Zafeiriadou E, Zavos C, et al. Serum vitamin B12 and folate levels in patients with non-alcoholic fatty liver disease. Int J Food Sci Nutr. 2012;63(6):659-66.
23. Hariri M, Zohdi S. Effect of Vitamin D on nonalcoholic fatty liver disease: a systematic review of randomized controlled clinical trials. Int J Prev Med. 2019;10:14.

Cite this article as: Sharma C, Badyal A. Association between vitamin B12 and non-alcoholic fatty liver disease: a case control study in Katra Jammu. Int J Basic Clin Pharmacol 2021;10:726-31. 